\title{
FORMATION OF THEORETICAL CONCEPTS IN THE PROCESS OF HISTORICAL-LITERARY COURSE STUDYING IN THE SENIOR CLASSES
}

\author{
Venera Amineva ${ }^{1}$, Landysh Yuzmukhametova ${ }^{2 *}$, Marsel' Ibragimov ${ }^{3}$, Elvira \\ Nagumanova $^{4}$ and Alsu Khabibullina ${ }^{5}$ \\ 1, 2,3,4,5 Kazan (Volga region) federal university, (Russia)
}

\begin{abstract}
Nowadays in the philological pedagogy, problem of the dialogue of cultures in the context of student-centered technology strategies of modern education attracts the scientists' attention. The learning activity nature is considered within the frame of the concept of the School of dialogue between cultures, extended and developed by V.S. Bibler. One of productive socio-cultural ideas in the field of humanitarian thinking is the idea of understanding and communication, the subject of which is a work of art: it is assumed that the modern reader joining the diverse cultural values of different times and nations, fixed in the literature, finds its unique place on their borders, " in the contact zone" with "foreign" cognitive, ethical and aesthetic sense.
\end{abstract}

The article reveals methodological principles of learning the composition of one literature in the context of its comparison with the other, providing a full extension of the reader's perception: orientation on genre-typological features of the compared works; characteristic of motivational structures used by writers; analysis of spatio-temporal relations embodied in the text, methods and techniques of psychological images, etc. The article distinguishes the ways of formation of theoretical notions of the national school pupils. The effective means of solving the problems that the teacher faces is comparative analysis of different national literature phenomena. It will help not only to understand the peculiarities of individual and creative artistic consciousness of the writers, patterns of the world literature but also those features of literature which give it its characteristic ethnic manifestation.

Keywords: national literature, dialogue, comparison, "own", "foreign", identity

\section{INTRODUCTION}

In modern science the need of conceptual studying the works of art and works of the writer in general, considered according to the ideological and art originality and from the point of a certain theoretical-literary problem view, doesn't raise doubts. One of the effective methods of learning of the theory of literature at school is the interpretative approach allowing to reveal logical consistency and semantic interrelation of semantic elements of this or that art tradition. It is used at a stage of specification of concept, its inclusion in new system of communications and applications to new material.
In the work "To methodology of the humanities" $\mathrm{M}$. M. Bakhtin, putting a problem of "understanding contexts" and differentiating small time of the present and big time, "close" and "far" contexts, writes about never-ending updating of meanings in all new contexts (Bakhtin, 1986: 392). The works of the Western European writers and at national school - literature, native for pupils, selected by the principle of typological proximity and also the greatest typicalness for the writer, region, eras can act as "an understanding context" of the 19th century Russian literature.

Comprehension of the system of the most important, representative categories of the Russian classical literature in the specific to them semantic and

Corresponding Author: *land_yz@mail.ru 
figurative field can be realized in various ways. Firstly, the accented research of terms, comparative analysis of concepts of different cultures are supposed to be significant. We consider as an example the distinctive features of an epic sort of literature finding similarities and distinctions in ways of art works creation by the writers representing different cultural traditions. The center of substantial space of epic work is the event understood in the broadest sense as "event" manifestation of regularities of life. Given rise from internal motives and actions of the person, it finds in the Russian literature inconsistent unity and integrity of the world, a combination of world communications certainty with independence and objectivity of all private, and in creativity of the east, in particular, belonging to Arab-Muslim culture writers - harmonious organization of all phenomena taking the constant place in the universe or aspiring to it on the descending hierarchy of their importance and rationality. Therefore the word "epos" in an arsenal of the east literature researcher is filled with a bit different contents in relation to its sense in the European culture. The "monumentalism" and "scale" of the creative act characteristic of the Western European and Russian writers actualise the principles of "harmony", "hierarchy" and "classification" correlating with them in an Arab-Muslim esthetics (Shidfar 1974: 108, 118-119, 150-151).

\section{METHOD}

The given research is within the context of cultures dialogue ideas as a form of their being in Big time, expressed in domestic science by M. M. Bakhtin (Bakhtin, 1979: 424). Works of domestic and foreign scholars (Iser, 1978; Iser, 1988; Iser, 1993; Ricoeur, 2002; Jauss, 1995; Jauss, 2004) that deal with the problem of perception and connected to it understanding are the methodological basis for scientific searches in the realm of literature dialogue and its projection to the sphere of teaching methods.

The study of dialogue between cultures and literatures found that «its participants enter the world of other artistic and aesthetic values. Moreover, they find their unique places in "zone of contact" with "foreign" cognitive, ethic and aesthetic meanings. In these conditions, the "foreign" either transforms to "other", "alien", "new" and finally "one's own" or remains something that could not and should not be used in one's own practice» (Amineva, 2014: 2096).

In a study of the dialogue between the Russian and Tatar literatures the structural, semiotic, hermeneutic, comparative methods; ethnopsychological and other interdisciplinary approaches needed to understand the spiritual and meaningful "appearance" of the compared literatures and cultures are used. Intercultural approaches found in the works of J.Birova (Birova, 2013, vol. 2; Birova, 2013, vol. 3) were also very useful for realizing our goals.

\section{RESULTS AND DISCUSSION}

The organizing beginning of epic works is the narration. From the authentic point of view (i.e. according to the tradition created its way of the speech material organization) the category of "the pointing to sense" was developed in the classical Arab-Muslim philological theory and having historically steady character more corresponds with the term 'narration' used in the Western European esthetics. Procedure of finding of sense, which demands as it is established by A. V. Smirnov not abstracting clarification from the specifying signs and transition from the hotel phenomena to that area which lies out of them and in which they coincide (Smirnov 2001: 308-309), is alternative to the genus-typological organizations of semantic units that is prepotent present at the European culture. Genus extension and typological narrowing of the word, which begins to include additional values, doesn't happen here as there is no sense increment also. But big "evidence" of the instruction on that sense which forms the last basis of any explanation is reached.

Rather representative "illustration" of the deep mechanisms operation defining universal and unique properties of each national literature is the organization of the subject sphere in the Russian realism of the XIX century and in works of the Tatar writers of the first third of the XX century. The hero finds sovereign internal space and is understood as "essentially nonobjectified, internally infinite and free personality" who is opened only to a look from inside (Broytman 2001: 273-274). As the 
corresponding researches testify, evolution of the Russian and European prose at the level of its subject space was in search of such narrative situation which would provide the author's nonpresence in relation to the hero becoming essentially nonidentical to himself, not coinciding with himself as with the subject.

S. N. Broytman characterizes the finishing position to so understood personality as follows: "It is "an equinox point" or "a zero point"... To appear in it, it is necessary to move not outside but inside, at the same time it has to be the movement to the border of the personality ( $\mathrm{I}$ - for - myself), to that limit where his consciousness is crossed with life ("another")" (Broytman 2001: 271). The scientist describes developed in classical (the second half of the 18th century - the 80th of the 19th century) and nonclassical (the end of the XIX-XX centuries) eras principles of art end of the hero. The allocated in works of M. M. Bakhtin and his followers ways of overcoming of traditional (monological) authorship crisis in works of the Russian realists of the 19th century are essential to us. So, in "Eugeniy Onegin" of A.S. Pushkin two approaches to heroes interact: they are given as the objectified images-characters and persons who are going beyond the character, in the found spiritual form receiving ability to cross border of heroes and to enter the novel of the novel. To these tendencies there corresponds the combination of two semantic structures creating the "separately existing identity" (N.D.Tamarchenko) of the author's image and heroes generated by primary author (Broytman 2001: 277-280).

The analytical realism of the middle of the 19th century tries to find nonpresense in relation to outlook and attitude of the hero developing under the internal laws of arbitrarily subject, having objectified character and secret identity. The increasing pansophy of the author, his activity in the field of a psychological explanation of acts, motives and experiences of characters is developed in notable limits. The psychological introspection doesn't get into an internal core of the personality, its main secrets remain out of the direct analysis: "One of signs of the storyteller's absolute power restriction is refusal of the hero's experiences objectification at especially significant moments of his spiritual life as it often occurs in I. Turgenev's works" (Broytman 2001: 281). V. M. Markovic investigating a position of the storyteller in the first four novels of I. S. Turgenev and the principles of the image of an interior also writes about it: "In the atmosphere of opposition of the general truth and the subjective truths restraint of the storyteller is subordinated to other tasks. "Party" of the hero gains relative independence also here, this independence is noticeably expressed in limitation of objective explanations range, in restraint of estimates, in existence of the basic default and partial half-words which aren't allowing interpretation of many sincere movements of the hero" (Markovic 1975: 43).

In Tolstoy and Dostoyevsky's creativity the character becomes the personality having consciousness. The consciousness as a subject of the image involves qualitatively new position of the storyteller and hero. An art position of the author in relation to the hero in the polyphonic novel of Dostoyevsky M. M. Bakhtin defines as "seriously the carried-out and up to the end realized dialogical position which approves independence, internal freedom, incompleteness and the hero's suspense. The hero for the author is not "he" and not "I" but complete "you" that is another strange full "I" ("you are")" (Bakhtin 1963: 84-84). New intension of the author and the new status of the hero transform a subject situation in literature: "the relation of the author and hero from the relation of the subject and object have raised into the relations between subjects" (Broytman 2001: 291).

In the Tatar prose there is other concept of the narration which challenges the right of the author "to be out of life and finish it". It means "deep distrust to any nonpresence" which Bakhtin compares to "God's immanentization" (Bakhtin 1986: 176). The author, as a rule, doesn't separate himself from the hero, listens to his word, gives him the chance to worry, think, speak up to the end, often even replacing himself with him. Forms of author's and personage's presence often aren't hierarchically differentiated, they are closely interconnected and directed to creation of the integrally pulled together in itself narration as conceptual self-disclosure and self-judgment of the events. Such subject forms which basis is not an analytical distinction of "I" and "another" but indivisibility of the author-creator and hero, certain integrity, intersubjective by its nature completness are formed. Such kind of archytectonics of esthetic 
object is caused by features of development of the personal beginning, character of a ratio of subject spheres "I" and "another", the author and the hero in the Tatar literature of the specified period. If we use categories of "personal" and "general", then it is necessary to recognize that between the hero and the author there is some proximity against the general proximity in the field of psychological space which belongs to "I" and "another" in that measure in what they are equally involved to God and the world. Single, psychologically concrete event moves as an actual form of unity, potentially infinite. Between the phenomena of the different semantic ranks substituted not in subordinative but in the coordinating relations the existential principle of "interpenetration" is established.

Thus, "intrapresence" becomes the esthetic principle allowing to learn the hero without finishing his image with a hasty assessment, without opposing to his subjective truth of the "authoritative" and "indisputable" word. This focus of the narration on forms of consciousness and types of characters' attitude isn't reduced to simple solidarity of the author with the hero and isn't equivalent to their romantic merge. "Intrapresence" is getting in the Tatar literature of the considered period the same constitutive value, as well as a position opposite to her - in the Russian realism of the 19th century.

Extra vital activity out of which the authorship is impossible is understood in the Tatar culture of this period differently than in the Russian. The point of view necessary for material organizing is given as the moral and ethical aim which is pursued by the author-creator and is adequate to her. It defines the author's shape. This purpose is spliced with esthetic object: it coincides with work composition, also it is affected by regularities of vertically horizontal folding of the whole sense, transferring, "coding" its existence.

Secondly, a contextual and hermeneutical method gives a lot of things for authentic understanding of national art traditions. Specifics of literary works of writers is defined by their rootedness in ethnic, linguistic, philosophical, religious and other contexts. Concepts of a context, extra text reality finding owing to this fact different meanings are used in various methodological traditions. The explanation of a context as the system of metameanings created on the basis of a certain outlook and realized in language - a factor causing national specifics of the text is important for us. However contextual approach conceals in itself as well danger of "leaving" from the internal immanent analysis of the text and the description of the corresponding realities, the valuable, standard, informative settings dominating in different cultures. Quite often these data precede and accompany a direct statement of historical-literary material as something absolutely external, necessary only as a background. Also the fact that distinctions are important not as the esthetic but as cultural fact demanding a systematic reduction to a certain nonliterary substratum attracts attention. Art and esthetic phenomena appear in the form of function from those conditions (social economic, geopolitical, culturological, etc.) in which the text is generated. Thereby literature is explained from psychological, sociological, ethnological and other points of view.

As it is represented, shortcomings of contextual approach can be overcome if mechanisms of interaction of the text and extra text ranks become objects of analyses and the attracted contexts (philosophical, religious, mythological, etc.) are thought not as addition of one explanation of material with another but as "mutually translated". Peculiar to the person of this or that culture features of worldview define type of the relations by which the author connects the subject with object, the ways of expansion of art systems subordinating the semantic world of the work, the organization of the subject sphere, plot forming regularities, etc. Interaction inside and extra text semantic fields is shown especially bright at the level of an internal form of the literary work. The category of a chronotope organizing internal cultural space and time of each nation and revealing features of worldview of these or those people is good example for it. It is established that idea of a primacy of spirit over matter is the cornerstone of the east type of thinking (time passes from the future to the present) that, in turn, leads to belief about primacy of time in relation to space, about predetermination, an invariance of the person's destiny, about futility of any his attempts of the life transformation. According to outlook of the western person, matter is primary, time passes from the present to the future 
and the personality allocated with strong will and commitment can dispose of his destiny.

In works of the Russian writers of the 19th century the space is often constituted by the hero. For example, in Dostoyevsky's novel "Idiot" transformation of internal space of drawing rooms, dining rooms, offices, bedrooms to "the carnival area" where under a psychological surface of the personality his ontology and metaphysics are opened is made by each of heroes captured by the excluding each other feelings, desires, intentions hesitating between opposite opportunities. Other type of the spatial relations is embodied in the Tatar prose of the beginning of the XX century: the person "incorporates" it, feels on himself the power of the spatial field which imposes on him, on his inner world its structure.

Spatial and time forms reflect also procedures of a meaning birth characteristic of this or that culture. From this point of view A. P. Chekhov's plays "The seagull" and F.Amirkhan's "Unequal" can be compared. Both Chekhov and Amirkhan were interested in eternal questions of life. But in the play of the Tatar playwright they aren't dominating and are considered along with others, not less important circle of the problems generated by the features of the concrete historical moment. Lines of eternity are more and more clearly in the events of the Chekhov's drama which are happened at present. Before the viewer several years pass but they contain in themselves all life of heroes - from the birth to death. Moreover, the feeling that many generations of people are related to sufferings and hopes of characters is created. If at Amirkhan the present is, first of all, time of a public situation modern to him, then at Chekhov the present is very relative and dissolved in the past and the future.

Semantic capacity of the spatial and time images arising in the play of Chekhov is created thanks to aspiration of the playwright to abstract regularities of life from concrete realities of life, to reveal and imprint eternal values of the universe in symbolical images, sign details. Time of "The seagull" is an eternity, the space covers all universe; remarks of heroes, scenery, separate images are symbolically ambiguous and filled with flickering shades of meanings. Ideological and esthetic semantics of a chronotope of the Tatar drama is another:
F.Amirkhan traces an immemorial inequality of people before Love, Existence in the world, the Destiny on the example of each concrete episode recreated on a scene of a realistic picture of life therefore time and space of "Unequal" are concrete and historical and are drawn towards unambiguity.

So, contextual and hermeneutical method allows to reconstruct the continual space defining specifics of art consciousness of this national culture; to reveal those parties of ideological and art integrity of the work which act as peculiar "channels" of tradition; to actualise "extra text" links of the work, its inclusiveness in historical and cultural, social and other discourses.

Finally, the pedagogical conceptionality of the school analysis is reached also by research of the dialogical relations arising between two literatures at which "the strange" is revealed from inside as out of and nearby standing, "the own", etc., but "own" is learned "through the another", reinterpreted from positions of "the strange". Different types of the relations of "the own" and "the strange" ("the own" opposed to "the strange"; "the own" polemizing with "the strange"; "the strange" as redesigned "the own", etc.) are revealed by comparison characteristic of writers - representatives of different world outlook formations - the principles of art perception of reality.

Classical Russian realism mastering the actual reality of public and private life of the people and at the same time going beyond this reality, by V. M. Markovic's words, to the "last" entities of society, history, mankind, the universe (Markovic 1993: 28) is directed to comprehension of determinancy of the events - social, psychological, anthropological, culturological and any other. Any art work of any time and direction establishes any connections and relations between the represented phenomena, assumes certain motivations of characters actions. Cause and effect dependences are found between two any phenomena which are artly mastered in the work but first of all in the sphere of acts and intentions of characters. Opposition of the motives and consequences organize structure of an artistic image and defines the image of an interior world of the person in the works of the 19th century Russian writers. For example, characters and behavior of heroes of "Eugene Onegin" are caused by 
environment, era, education by the traditions, stereotypes connected with their social state, cultural codes, in particular literary models. Terrible, relentless reality puts a limit to impudent, freedom-loving rushes of heroes of $\mathrm{M}$. $\mathrm{Yu}$. Lermontov. It dictates living position of Pechorin, his "demonism" and individualism. Oblomov's destiny in I. A. Goncharov's novel is result of influence of the environment interpreted rather widely as patriarchal way of the Russian life not only with negative but also with deeply poetic parties. The outlook and destiny of Bazarov in "Fathers and children" are defined by naturalscience representations which conflict to needs of love and happiness. "Worrying analytical", according to A. V. Chicherin's characteristic, L. N. Tolstoy's method assumes consideration of the conditionality which is at the same time operating at the different levels of spiritual human life. The logician of motivations in novels of Dostoyevsky is subordinated to the movement of the ideas embodied by heroes.

The central for the Russian realism of the XIX century problem of the determinism, conditionality of behavior and consciousness of heroes by various circumstances, whether it is idea, cultural codes or the social "microenvironment" surrounding the person, is actualized by comparison to works of the Tatar writers of the first third of the XX century. Their efforts are pointed to the to search and the proof of existence of the most deserving attention fact but not its interpretation, an explanation of causes and effects because that and another is thought as something set to the described reality. The center of the art world is not so much the personality in his public relations, environment, era, cultural tradition but the status of the personality, his qualities in valuable moral potentialities. Heroes are presented in their art certainty: the person is transcendental in the spiritual essence and there is the fact that he is and any defining factors don't explain in him anything and nothing add to him.

In historical-literary situations when we need to reconsider a habitual view of the world, the settled rules and norms there are searches of new art means and receptions, the following type of the dialogical relations is actualised: "the own" as redesigned "the strange". Functioning of the Russian psychological prose traditions in the Tatar literature of the first third of the 20th century is remarkable in this plan. In it the principles and receptions of the psychological image characteristic of "dialectics of soul" - the form of the psychological analysis which has found classical expression in L. N. Tolstoy's creativity have gained development. Two defining experiences of the person of modern time (a comprehensive reorganization of social orders and crisis of a former miropicture) are transformed by the Russian and Tatar writers to the existential, intellectual, moral, psychological biography of heroes as carriers of the deepest problems of the era. Mental process and its knowledge synchronize different types of internal monologues (logical, associative, etc.). L. Tolstoy's heroes are captured by irresistible desire to resolve the deepest questions of life of the person - philosophical problems of war and peace, moral behavior, an intellectual responsible attitude to themselves and to others, etc. The system generating factors of the psychological dramas represented by the writer are logic of binary models (freedom and need, destiny and an occasion, spiritual and material, the phenomena and entities, a moment and eternity, final and infinite, etc.) and lack of "the neutral axiological sphere" (Ю, M. Lotman, B. A. Uspensky). These are a condition of internal disintegration and chaos in which there are Pierre after duel with Dolokhov, execution of prisoners, the social dramas endured by Levin and other utopian seekers or representatives of the educational moralizing cultural tradition (Bolkonsky, Nekhlyudov, etc.). Contradiction of the universal oppositions is the cornerstone of all attempts of heroes to conceptualize the phenomena of reality and own spiritual experience. So, life history of Pierre Bezoukhov as G. B. Kurlyandskaya shows is given from the point of correlation of "consciousness" and "activity", "life" (Kurlyandskaya 186-215). Andrey Bolkonsky constantly occurs before the choice between two behavior models: "to live for others" or "to live for himself". Deepening of interest in conflict aspects of life, dialectics of tragic consciousness, according to O. N. Osmolovsky, leads to the fact that the "dialectics of soul" which was the main method of the image of Tolstoy's characters untill 70th is transformed to dialectics of psychological polarity (Osmolovsky 1981: 126). The psychology of 
spiritual bifurcation changes structure of internal monologues doing them more dialogised.

In this plan art searches of Tolstoy become closer to approaches and ways of reproduction of spiritual and psychological life characteristic of Dostoyevsky. Internal monologues in his works, in the most part, and close to them forms of not actually direct speech are dialogised and reflect throwings between antagonistic powers of consciousness, sharp change of opposite states and feelings, their interaction and simultaneous existence, continuous collision of affine emotions. In works of the Tatar writers the similar forms of the psychological image, revealing special qualities of the person again and again appearing in a situation of the choice, living in the world where there is nothing predetermined once and for all, no programmed invariable course of life, are used. Thus, the culture of search bringing itself out of own limits, culture of open opportunities is actualised.

The dialogue which is carried out as a meeting and interface of various semantic and stylistic structures reveals a role of national art values in world literary process, their internal potential from the point of view of the stimulating influence outside a domestic context. At the same time "the own" appears as participating in formation of "the strange", is enriched with additional meanings which are born by the dialogical relations with "the strange". Various types of the dialogical relations which are established between the art texts belonging to different national traditions become essential to idea of forms of interliterary process, and also each of literatures as about difficult constructed and internally connected integrity. The position of "nonpresence" of one literature in relation to another gives the chance of other, its new vision, inaccessible to a look "from inside", introspection position.

So, theoretical-literary concepts demand for the comprehension the thinking not only formal and abstract but also contextual and narrative. At the same time an effective method of the problems facing the teacher is the contrastive and comparative analysis of the phenomena of different national literatures helping to understand not only an originality of individual creative art consciousness of the writer, regularities of world literary process but also those features of literature which give it characteristic ethnic demonstration.

\section{ACKNOWLEDGEMENT}

The research is performed according to the Russian Government Program of Competitive Growth of Kazan Federal University

\section{REFERENCES}

Amineva, V.R. (2014). "Universal" and "Unique" as the Categories of Comparative Literature. Middle-East Journal of Scientific Research, 20 (12), 2094-2098.

Bakhtin, M. M. (1963) Problems of poetics of Dostoyevsky. M.: Soviet writer, 364 p.

Bakhtin, M.M. (1979). Aesthetic of Word Creative Work. Moscow: "Iskusstvo", pp: 424.

Bakhtin, M. M. (1986). Estetika of verbal creativity. 2nd prod. M.: Art, 445 p.

Bekmetov, R.F. (2015). About the "Buddhist View" on Russian Literature. Mediterranean Journal of Social Sciences, 6 (3), 9-17.

Birova, J. (2013). About Theoretical Definitions of Pluralistic and Pluricultural Approaches. XLinguae, European Scientific Language Journal, 6 (2), 2013, 91-103.

Birova, J. (2013). Pluralistic and pluricultural approaches intuitively applied by teachers of French. XLinguae, European Scientific Language Journal, 6 (3), 76-100.

Broytman, S. N. (2001). Istoricheskaya poetics. M.: RGGU, $320 \mathrm{p}$.

Iser, W. (1978). The Act of Reading: A Theory of Aesthetic Response. Baltimore, London: The John Hopldns University Press. 252 p.

Iser, W. (1988). The Reading Process: a Phenomenological approach. Modern Criticism and Theory. A reader. Edited by David Lodge. London, New York: Longman. 467 p.

Iser, W. (1993). The Active and the imaginary: Charting literary anthropology. Baltimore: Johns Hopkins UP. 380 p.

Jauss, H.R. (1995). The history of literature as a literary provocation. New Literary Review, 12, 34-84.

Jauss, H.R. (2004). The history of literature as a challenge to the theory of literature. Modern Literary Theory: Anthology. M.: Flint: Science, 192-200.

Kurlyandskaya, G. B. (1988). Moral ideal of heroes L. N. Tolstoy and F. M. Dostoyevsky: Book. For the teacher. M.: Education, $256 \mathrm{p}$.

Markovic, V. M. (1993) Question about the literary directions and creation of history of the Russian literature of the XIX century. The News. Russian Academy of Sciences. Otd. literature and language. No. 3. 26-32.

Markovic, V.M. (1975). Chelovek in novels I. S. Turgeneva. L.: Publishing house of the Leningrad university, $152 \mathrm{p}$.

Osmolovsky, O. N. (1981). Dostoyevsky and Russian psychological novel. Chisinau: "ShTIINTsA", 168 p. 
Smirnov, A.V. (2001). Nominalnost and pithiness: why noncritical research of "culture universaliya" threatens with delusion. Universaliya of east cultures. M.: East Literature book-publishing firm of the Russian Academy of Sciences, 290-317, 346-382.

Shidfar, B. Ya. (1974). Figurative system of the Arab classical literature (the VI-XII centuries). M.: Science. Main edition of east literature, $254 \mathrm{p}$.

Ricoeur, P. (2002). Conflict of interpretations. Essays on hermeneutics. M.: «CANON- press - C»; «Kuchkovo pole». $624 \mathrm{p}$. 